\title{
The relation between dietary phytochemical index and metabolic syndrome and its components in a large sample of Iranian adults: a population- based study
}

\author{
Azam Ahmadi Vasmehjani ${ }^{1,2}$, Zahra Darabi $^{1,2}$, Azadeh Nadjarzadeh ${ }^{1,2}$, Masoud Mirzaei $^{3}$ and
} Mahdieh Hosseinzadeh ${ }^{1,2^{*}}$ (D)

\begin{abstract}
Background: Despite the protective effects of foods being rich in phytochemicals against chronic diseases, this issue is still poorly understood. The aim of this study was to investigate the association between Dietary Phytochemical Index (DPI) and metabolic syndrome (MetS) and its components.

Methods: This cross-sectional study focused on adults aged between 20 and 70years. The dietary intake was assessed using a validated and reliable food frequency questionnaire. DPI was calculated based on dietary energy, derived from phytochemical-rich food sources ( $\mathrm{kcal}$ ) per total daily energy intake (kcal). The odds ratio of MetS and its components were assessed across DPI quartiles by logistic regression models.
\end{abstract}

Results: After adjustment for all potential confounders, the risk of MetS (OR: 0.63, 95\% Cl=0.41-0.96) and elevated blood pressure (OR: $0.62,95 \% \mathrm{Cl}=0.40-0.96)$ in the second category of DPI decreased significantly as compared to that in the first category. Subjects in the second and fourth quartiles of DPI with adjusting for age, sex and total energy intake revealed 30 and $25 \%$ lower risk of abdominal obesity, respectively. After full adjustment for confounders, the analysis stratified by sex showed women in the highest quartile of DPI had 59\% lower risk of MetS (OR: $0.41,95 \% \mathrm{Cl}=0.22-0.76)$ as compared to those in the lowest quartile of DPI.

Conclusions: Greater adherence to phytochemical-rich diet could reduce odds of MetS and some components, especially in women. Further studies with intervention approaches are recommended.

Keywords: Dietary phytochemical index, Metabolic syndrome, Phytochemical-rich foods, Triglyceride, Hypertension, Iran

\footnotetext{
* Correspondence: hoseinzade.mahdie@gmail.com

${ }^{1}$ Nutrition and Food Security Research Center, School of Public Health,

Shahid Sadoughi University of Medical Sciences, Yazd, Iran

2Department of Nutrition, School of Public Health, Shahid Sadughi University

of Medical Sciences, Yazd, Iran

Full list of author information is available at the end of the article
}

C C The Author(s). 2021 Open Access This article is licensed under a Creative Commons Attribution 4.0 International License, which permits use, sharing, adaptation, distribution and reproduction in any medium or format, as long as you give appropriate credit to the original author(s) and the source, provide a link to the Creative Commons licence, and indicate if changes were made. The images or other third party material in this article are included in the article's Creative Commons licence, unless indicated otherwise in a credit line to the material. If material is not included in the article's Creative Commons licence and your intended use is not permitted by statutory regulation or exceeds the permitted use, you will need to obtain permission directly from the copyright holder. To view a copy of this licence, visit http://creativecommons.org/licenses/by/4.0/. The Creative Commons Public Domain Dedication waiver (http://creativecommons.org/publicdomain/zero/1.0/) applies to the data made available in this article, unless otherwise stated in a credit line to the data. 


\section{Background}

A set of cardiovascular risk factors including abdominal obesity, hypertension, dyslipidemia, glucose intolerance, and insulin resistance indicates Metabolic Syndrome (MetS) [1, 2]. The global prevalence of MetS has been reported from smaller than 10 to $85 \%$ [3]. Recent national data showed that more than $30 \%$ of Iranian adults suffer MetS [4]. Various factors including race, family history of diabetes, hypertension and heart disease, genetics, age, gender, lifestyle, diet and obesity are involved in the development of MetS [5, 6]. Identification of the modifiable factors such as diet is essential to prevent the development of MetS [7].

Former studies have demonstrated that increased levels of saturated fat and cholesterol [8], animal protein $[9,10]$, and high glycemic index diet [11] lead to the risk of MetS. In contrast, higher intake of unsaturated fat [8], fruit and vegetables [12] help reduce the risk of MetS.

Longstanding studies on the aforementioned issue have focused on nutrients, foods, and food groups, with less emphasis on dietary patterns. Since nutrient interactions cannot fully explain the association between food and chronic disease, dietary patterns have been proposed as a new approach in nutritional studies $[13,14]$. Recently, nutritionists have focused on the combined effects of food, proposing a multivariate approach of food patterns [15]. The findings of these studies have proven that the Mediterranean dietary pattern which is rich in vegetables and fruit, nuts, legumes, olive oil; low in saturated fat, red meat and poultry; moderate in fish; and low to medium in dairy products yield beneficial health effects through phytochemicals [16]. Phytochemicals are natural non-nutritive bioactive compounds including phenolic, isoperenoids and organosulfor compounds [17, 18]. Due to the health-boosting effects of phytochemicals, dietary phytochemical index (DPI) was suggested by McCarty, which is defined as a percentage of calories derived from food rich in phytochemicals [17]. DPI calculation seems to be a simple and inexpensive method of assessing the background of dietary quality as well as clinical applications [19].

So far, some studies have examined the relationship between DPI and health indicators including oxidative stress, inflammation, cancer and mental health [20-22]. Prior findings have shown that an affluent diet in phytochemicals via antioxidant and anti-inflammatory properties plays a protective role in the development of insulin resistance, abnormal glucose, lipid disturbances and abdominal obesity [23-26]. However, the relation between DPI and the occurrence of MetS is still poorly understood. As such, the purpose of this study was to investigate the association between DPI and the risk of developing MetS and its components in a large population of Iranian adults.

\section{Methods}

\section{Study design and participants}

This cross-sectional study was carried out on data obtained from recruitment phase of Yazd Health Study (YaHS) and Taghzieh Mardom-e-YaZd (TAMYZ) conducted from 2014 to 2016. YaHS is a population-based prospective cohort study of 10,000 people aged $20-70$ years who randomly selected from 200 clusters (50 each, 25 men and 25 women and 5 persons in each ten years age groups) of Yazd greater area according to the city post codes. TAMYZ was a nutrition sub-study of YaHS which was conducted on the same 10,000 participants, however only 8000 of them were participated. Over 100 trained interviewers visited the participants at their residence after set up meeting time and then filled a validated questionnaire with 300 questions including dietary intakes demographics and physical activity. All participants were invited to attend a referral laboratory within two weeks from the interview date to provide fasting blood sample for biochemical assessments. The profile of the studies was published elsewhere [27].

Almost $40 \%$ of the YaHs participants gave consent for fasting blood sampling and biochemical assessment; there was no significant difference between those who attends and those who do not attend in terms of major SES factors. Out of 3748 available cases with data on dietary intakes, blood tests and main variables associated with MetS, the subjects with following conditions were excluded: having history of diseases such as diabetes mellitus, cardiovascular diseases, stroke and cancer or persons whose total daily energy intake was less than 800 or higher than 6500 $\mathrm{kcal}$ and missing data. Finally, 2326 subjects were included in this analysis. Flowchart of the data collection process is shown in Fig. 1.

Written informed consent was obtained from all participants. Ethical approval was obtained from the Ethics Committee of Shahid Sadoughi University of Medical Sciences, IR.SSU.SPH.REC.1399.051. YaHS database is not publically available. The authors assess the data according to the study protocol and agreement with the CI of study Professor Masoud Mirzaei who critically read and comment on this manuscript.

\section{Dietary assessment}

Dietary intakes were assessed through a validated (FFQ) consisting of 178 food items which was modified version of a previously validated 168-item FFQ. Additional 10 questions relating to consumption of Yazd-specific food items were added to the original FFQ that were collected by trained interviewers [27, 28]. Participants were asked about the frequency and usual amount consumption of food items in the past year then were converted to grams using guidelines of household scales [29]. 


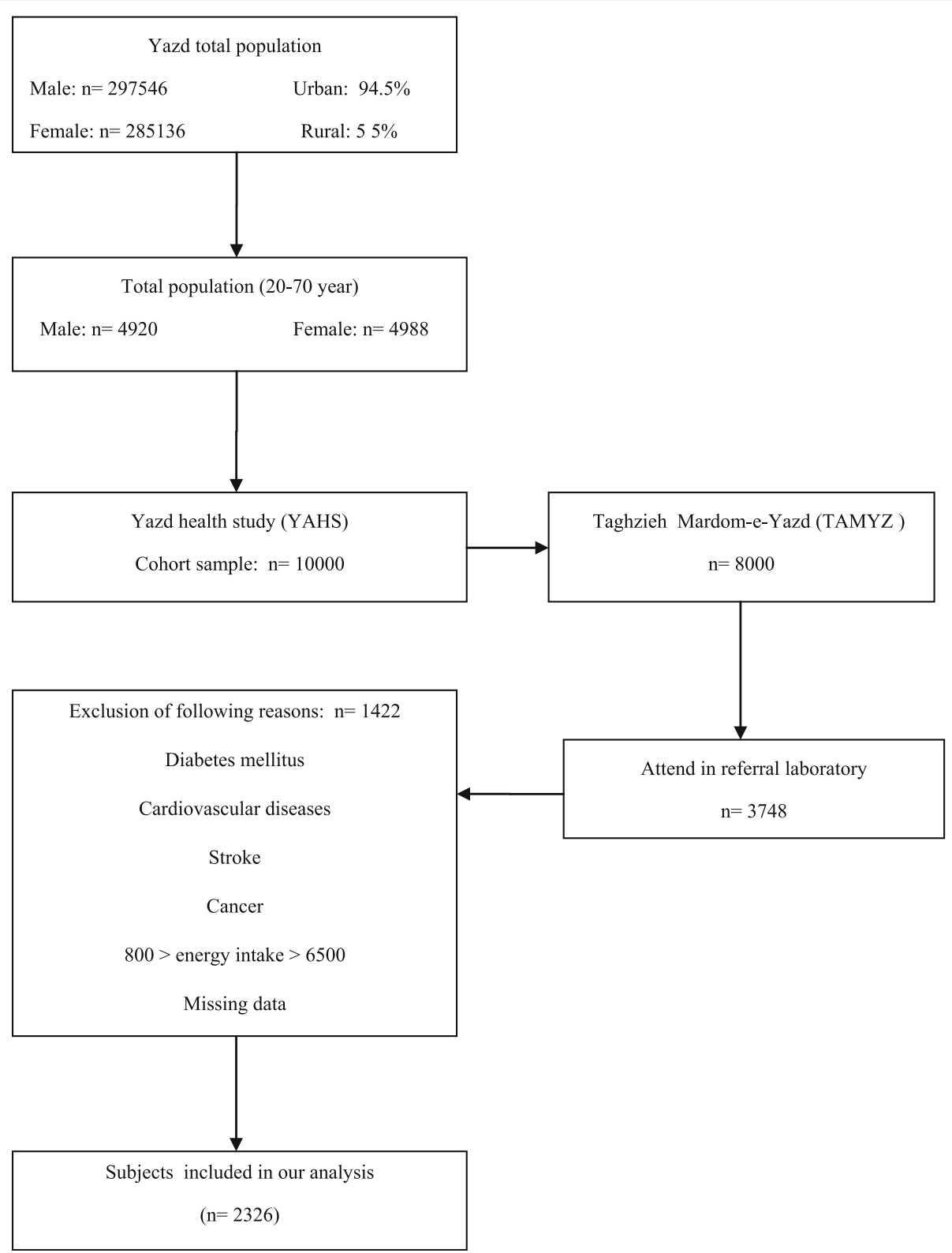

Fig. 1 Flowchart of the data collection process of study

\section{Phytochemical index calculation}

The DPI was calculated based on the method developed by McCarty in 2004; [ [DPI = (daily energy derived from phytochemical-rich foods (kcal)/total daily energy intake $(\mathrm{kcal})) \times 100$ ) [17]. Fruits, vegetables, legumes, whole grains, nuts, soy products, seeds and extra virgin olive oil were considered as phytochemical-rich foods. Coffee and tea, as free energy sources, were not contributed. Potatoes were not included as vegetables because of their low phytochemicals content. Natural fruit and vegetable juices as well as tomato sauces were included in the fruit and vegetable groups because of their high phytochemical content $[16,17,22]$.

\section{Anthropometric assessments}

Weight was measured using Omron BF-511 portable digital scales to the nearest $0.1 \mathrm{~kg}$ with minimum clothing and in standing position on scale. Height was measured using tape measure on a straight wall to the nearest $0.1 \mathrm{~cm}$, in a standing position without shoes by touching shoulders, buttocks and heels to the wall and head in Frankfurt position. Waist circumference (WC) was measured to the nearest $0.5 \mathrm{~cm}$ using non-stretch tape meter, while it is middle of the iliac crown and lowest rib in the standing position. Also, hip circumference was measured from the largest part of the buttocks with an accuracy $0.5 \mathrm{~cm}$. Body mass index (BMI) 
is calculated by dividing weight $(\mathrm{kg})$ to the square of height $\left(\mathrm{m}^{2}\right)$.

\section{Physical activity assessment}

The short form International Physical Activity Questionnaire (IPAQ) was used to assess frequency and time spent on sedentary, moderate, intensity activities, according to the list of common activities of daily life, over the past week. Activity levels were expressed as Metabolic Equivalent (MET) hours per week [30].

\section{Diagnosis of metabolic syndrome}

MetS was diagnosed according to National Cholesterol Education Program Adult Treatment Panel III (NCEP ATP III). Participants who had at least three of following criteria were diagnosed as participant with MetS: Serum triglycerides $\geq 150 \mathrm{mg} / \mathrm{dL}$; Serum high-density lipoprotein cholesterol (HDL-C) $<40 \mathrm{mg}$ $\mathrm{dL}$ for men and HDL-C $<50 \mathrm{mg} / \mathrm{dL}$ for women; Fasting blood glucose $\geq 100 \mathrm{mg} / \mathrm{dL}$; Blood pressure $\geq 130$ / $85 \mathrm{mmHg}$ and waist circumference $\geq 102 \mathrm{~cm}$ for men and $>88 \mathrm{~cm}$ for women [31].

\section{Laboratory measurements}

Laboratory measurements included of fasting blood glucose, HDL-C and triglycerides were measured according to a standard laboratory protocol using Pars Azmoon kits (Tehran, Iran) and calibrated Ciba Corning (Switzerland) auto-analysers.

\section{Assessment of other variables}

Blood pressure was measured in a sitting position three times with a 5-min interval between each measurement. Other data including age, gender, marital status, education, job status and history of chronic diseases were collected by trained interviewers.

\section{Statistical analysis}

DPI was categorized based on quartiles ranges. Characteristics of participants were compared throughout quartiles of DPI using one-way analysis for continuous variables and Chi-squared test for non-continuous. To estimate odds ratio and 95\% confidence interval (OR (95\%CIs)) of MetS and its components in each quartile DPI and overall trend was used binary logistic regressions in crude and multivariable-adjusted models. Analysis stratified by sex were conducted in crude and multivariable-adjusted models. Possible confounders which were considered in models were age (y), sex (men/women) and total energy intake ( $\mathrm{kcal} /$ day) in the first model. Marital status (married/single/divorce/ widowed), physical activity level (sedentary/moderate/active), smoking status (never/former/current), family history of chronic disease (yes/no), educational level (less than high school diploma/college/ university), job status (not employed/employed), house status (owner/not owner), family size (less than $4 /$ more than five), house in square meters (less than 100 square meters/ between 100 to 200 square meters/more than 200 square meters), ethnicity (Native or non-native) in the second model. Along with other variables of the second model, BMI $\left(\mathrm{kg} / \mathrm{m}^{2}\right)$ was considered in the third model. Statistical analyses were performed by SPSS statistical software (version 23). $P$ values less than 0.05 was statistically considered for significant level.

\section{Results}

General characteristics of the study participants across categories of DPI are presented in Table 1. Mean (SD) of DPI among the first, second, third and fourth quartiles categories was 12.5 (3.15), 19.4 (1.36), 24.53 (1.79) and 36.08 (9.2), respectively. There were no significant differences in BMI, WC, marital status, education, smoking, job status and physical activity levels across quartiles of DPI. The prevalence of MetS and its components was not significantly different across quartiles of DPI except for abdominal obesity $(P=0.04)$.

\section{Dietary intake and DPI}

Mean dietary intakes of participants across quartiles of DPI are provided in Table 2. Participants in the upper quartile of DPI have higher intakes of whole grain, vegetables, fruits, legumes, nuts, vitamins $\mathrm{C}$, vitamin $\mathrm{A}$, folic acid, pantothenic acid, iron and potassium compare with those in the bottom quartile $(p<0.001)$. Participants in the highest DPI compare to the lowest, have lower intake of energy, total fat, monounsaturated fatty acids (MUFA), saturated fatty acids (SFA), polyunsaturated fatty acids (PUFA), cholesterol, total fiber, vitamin E, zinc, calcium, magnesium $(p<0.001)$. No significant difference was observed across quartiles of DPI for Docosahexaenoic acid (DHA) and Eicosapentaenoic acid (EPA) intake.

\section{DPI and MetS and its components}

The odds ratio and (95\% CIs) of MetS and its components across quartiles of DPI are presented in Table 3. After adjustment for age, sex and energy intake, the risk of MetS (OR: 0.72, 95\% CI $=0.55-0.93, P=0.01$ ) and abdominal obesity (OR: $0.70,95 \% \mathrm{CI}=0.53-0.93, \mathrm{P}=0.01$ ) decreased significantly in the second quartiles of DPI compared to the first. Also odds of abdominal obesity in the fourth quartiles of DPI compared to the first, was significantly decreased (OR: $0.75,95 \% \mathrm{CI}=0.58-0.99$, $P=0.04$ ). In addition to the risk of MetS (OR: $0.58,95 \%$ $\mathrm{CI}=0.38-0.88, P=0.01)$ and elevated blood pressure (OR: $0.59,95 \% \mathrm{CI}=0.38-0.92, P=0.02$ ) decreased in the second quartile of DPI compared to the first after 
Table 1 General characteristics of the study participants according to quartiles of DPI

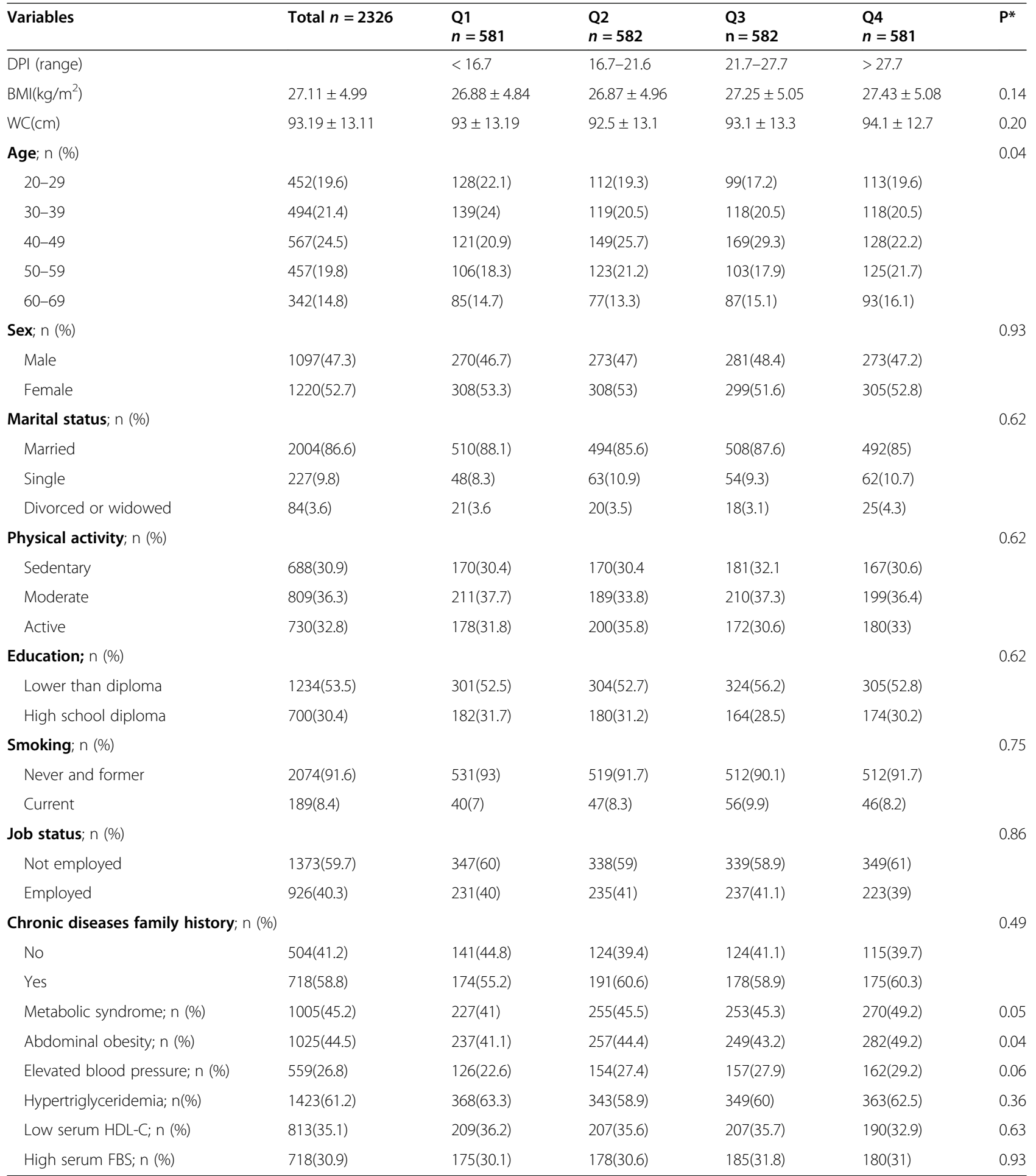

BMI Body mass index, WC Waist circumference, DPI Dietary phytochemical index, HDL-C High-density lipoprotein cholesterol, FBS Fasting blood sugar, Q quartile, SD Standard deviation

Data are shown mean \pm SD for BMI, WC and $\mathrm{n}(\%)$ for categorical variables. $P$-Value from ANOVA for continious variables and Chi - square test for categorical. $P$ Values $<0.05$ was considered significant

further adjustments for marriage status, physical activity, education level, Smoking, job status, house status, family size, house in meters, ethnicity, hypercholesterolemia, chronic disease family history. In the third model, the risk of MetS (OR: 0.63, 95\% CI $=0.41-0.96, P=0.03$ ) and elevated blood pressure (OR: $0.62,95 \% \mathrm{CI}=0.40$ 
Table 2 Mean dietary intake of participants by categories of DPI $(n=2326)$

\begin{tabular}{|c|c|c|c|c|c|c|c|c|c|c|c|}
\hline \multirow[b]{2}{*}{ Variables } & \multicolumn{2}{|c|}{$\begin{array}{l}\text { Total } \\
n=2326\end{array}$} & \multicolumn{2}{|l|}{$\begin{array}{l}\text { Q1 } \\
n=581\end{array}$} & \multicolumn{2}{|l|}{$\begin{array}{l}\text { Q2 } \\
n=582\end{array}$} & \multicolumn{2}{|l|}{$\begin{array}{l}Q 3 \\
n=582\end{array}$} & \multicolumn{2}{|l|}{$\begin{array}{l}\mathrm{Q} 4 \\
\mathrm{n}=581\end{array}$} & \multirow[t]{2}{*}{$P^{*}$} \\
\hline & mean & SD & mean & SD & mean & SD & mean & SD & mean & SD & \\
\hline Dietary PI & 23.13 & 9.95 & 12.5 & 3.15 & 19.4 & 1.36 & 24.53 & 1.79 & 36.08 & 9.2 & $<0.001$ \\
\hline Energy (kca/day) & 2863.76 & 1298.27 & 3520.42 & 1440.08 & 2650.68 & 1219.47 & 2495.22 & 1110.39 & 2789.73 & 1157.02 & $<0.001$ \\
\hline Protein(g/day) & 113.8 & 58.98 & 133.26 & 69.13 & 107.93 & 57.99 & 102.37 & 46.91 & 111.65 & 55.18 & $<0.001$ \\
\hline Carbohydrate(g/day) & 402.76 & 213.28 & 498.40 & 277.58 & 363.92 & 177.14 & 345.38 & 160.65 & 403.52 & 184.49 & $<0.001$ \\
\hline Total Fat(g/day) & 111.76 & 72.15 & 156.78 & 93.97 & 101.80 & 59.99 & 92.27 & 52.12 & 96.24 & 54.41 & $<0.001$ \\
\hline Cholesterol(mg/day) & 394.11 & 382.97 & 501.18 & 578.68 & 385.51 & 325.27 & 352.21 & 261.88 & 337.64 & 248.73 & $<0.001$ \\
\hline SFA (g/day) & 31.11 & 18.12 & 41.75 & 23.15 & 29.47 & 16.17 & 26.84 & 13.60 & 26.38 & 13.29 & $<0.001$ \\
\hline MUFA (g/day) & 34.36 & 24.52 & 48.61 & 32.36 & 31.65 & 21.08 & 28.07 & 17.59 & 29.13 & 18.16 & $<0.001$ \\
\hline PUFA (g/day) & 28.54 & 24.21 & 36.71 & 31.02 & 25.40 & 20.29 & 23.20 & 15.67 & 28.85 & 24.98 & $<0.001$ \\
\hline $\mathrm{EPA}(\mathrm{mg} /$ day) & 0.02 & 0.08 & 0.02 & 0.09 & 0.02 & 0.1 & 0.02 & 0.07 & 0.02 & 0.05 & 0.742 \\
\hline $\mathrm{DHA}(\mathrm{mg} /$ day $)$ & 0.07 & 0.21 & 0.07 & 0.25 & 0.07 & 0.26 & 0.07 & 0.19 & 0.06 & 0.14 & 0.686 \\
\hline Total Fiber(g/day) & 27.68 & 24.21 & 33.70 & 33.24 & 22.83 & 15.83 & 24.48 & 22.51 & 29.71 & 20.31 & $<0.001$ \\
\hline Vitamin E (mg/day) & 11.12 & 11.38 & 12.43 & 12.92 & 11.49 & 11.20 & 10.52 & 10.44 & 10.02 & 10.67 & $<0.001$ \\
\hline Vitamin A (RAE/day) & 23.38 & 33.91 & 19.11 & 15.64 & 19.77 & 27.55 & 20.07 & 18.52 & 34.57 & 55.62 & $<0.001$ \\
\hline Vitamin D( $\mu \mathrm{g} /$ day $)$ & 1.49 & 2.40 & 1.85 & 3.67 & 1.46 & 1.73 & 1.48 & 2.33 & 1.18 & 1.04 & $<0.001$ \\
\hline Vitamin K( $\mu \mathrm{g} /$ day $)$ & 166.04 & 243.82 & 191.19 & 349.82 & 160.03 & 224.99 & 160.26 & 175.61 & 152.70 & 182.90 & $<0.001$ \\
\hline Vitamin C(mg/day) & 207.27 & 181.14 & 164.09 & 111.82 & 182.77 & 135.30 & 202.85 & 142.61 & 279.43 & 269.46 & $<0.001$ \\
\hline Folic acid( $\mu \mathrm{g} /$ day $)$ & 371.68 & 211.10 & 377.25 & 194.99 & 336.60 & 200.11 & 341.72 & 169.03 & 431.26 & 257.21 & $<0.001$ \\
\hline VitaminB12( $\mu \mathrm{g} /$ day $)$ & 6.03 & 5.92 & 7.51 & 7.01 & 6.07 & 5.75 & 5.42 & 4.33 & 5.1302 & 6.02 & $<0.001$ \\
\hline Magnesium(mg/day) & 335.41 & 172.25 & 363.17 & 176.91 & 308.04 & 165.64 & 307.91 & 154.04 & 362.64 & 182.63 & $<0.001$ \\
\hline Potassium(mg/day) & 4072.06 & 2098.04 & 4197.37 & 1950.44 & 3652.56 & 1823.79 & 3810.11 & 1869.87 & 4629.36 & 2536.55 & $<0.001$ \\
\hline Zinc (mg/day) & 11.90 & 5.93 & 13.66 & 7.05 & 11.17 & 5.63 & 10.77 & 4.71 & 11.98 & 5.67 & $<0.001$ \\
\hline $\mathrm{Fe}(\mathrm{mg} /$ day $)$ & 42.33 & 56.92 & 38.28 & 46.98 & 38.99 & 44.58 & 39.77 & 44.42 & 52.29 & 81.72 & $<0.001$ \\
\hline Fruits(g/day) & 585.45 & 512.03 & 386.67 & 264.58 & 495.06 & 356.73 & 604.30 & 418.80 & 855.89 & 745.9 & $<0.001$ \\
\hline Vegetables (g/day) & 216.26 & 246.33 & 198. 7 & 235.6 & 196.85 & 158.86 & 215.69 & 297.83 & 253.82 & 267.4 & $<0.001$ \\
\hline Legumes (g/day) & 47.25 & 58.01 & 45.42 & 59.78 & 40.95 & 38.98 & 44.11 & 36.19 & 58.55 & 83.09 & $<0.001$ \\
\hline Nuts (g/day) & 23.01 & 34.01 & 25.84 & 34.20 & 17.21 & 20.59 & 18.02 & 22.16 & 31.01 & 49.18 & $<0.001$ \\
\hline Whole grains (g/day) & 73.55 & 68.49 & 49.41 & 53.29 & 68.66 & 51.01 & 77.01 & 59.27 & 99.11 & 92.54 & $<0.001$ \\
\hline Fructose (g/day) & 30.67 & 28.36 & 36.15 & 41.40 & 26.82 & 20.24 & 26.78 & 18.95 & 32.94 & 25.98 & $<0.001$ \\
\hline
\end{tabular}

DHA Docosahexaenoic acid, MUFA Monounsaturated fatty acid, SFA Saturated fatty acid, PUFA Polyunsaturated fatty acids, EPA Eicosapentaenoic acid DPI Dietary phytochemical index, Data are shown mean \pm SD, ${ }^{*}$ Pvalues from ANOVA and were considered $<0.05$ significant

0.96, $\mathrm{P}=0.03$ ) significantly decreased in the second quartile of DPI compared to the first in full adjustmens. There was not any significant relationship between DPI and other components of MetS in crud and full adjustments model (data are not shown).

\section{DPI and MetS its components stratified by gender}

Odds ratio (95\% CIs) of MetS across different categories of DPI stratified by sex are shown in Table 4. In women, after adjustment for confounders, risk of MetS significantly decreased in the highest quartile of DPI as compared to the lowest (OR: $0.41,95 \% \mathrm{CI}=0.22-0.76, P=$ 0.005). There was not any significant relationship between DPI and MetS components stratified by sex (data are not shown).

\section{Discussion}

The findings of the present study indicated a reduction risk of high blood pressure and MetS with higher adherence to DPI after adjusting a wide range of possible confounder variables. Decrease in the risk of abdominal obesity was associated with higher DPI scores, independent of age, sex and total energy intake. Women with most conformity of DPI showed lower odds of MetS. These findings remained significant after a full adjustment for confounders. Due to the insufficient evidences 
Table $3 \mathrm{OR}(95 \% \mathrm{Cl})$ for metabolic syndrome and its components according to quartiles of DPI

\begin{tabular}{|c|c|c|c|c|c|}
\hline Variables & $\begin{array}{l}\text { Q1 } \\
(n=581)\end{array}$ & $\begin{array}{l}\text { Q2 } \\
(n=582)\end{array}$ & $\begin{array}{l}\text { Q3 } \\
(n=582)\end{array}$ & $\begin{array}{l}\text { Q4 } \\
(n=581)\end{array}$ & $P$ trend \\
\hline \multicolumn{6}{|c|}{ Metabolic syndrome } \\
\hline Crude & 1 (ref.) & $\begin{array}{l}0.71(0.56-0.91) \\
P=0.006\end{array}$ & $\begin{array}{l}0.86(0.68-1.09) \\
P=0.22\end{array}$ & $\begin{array}{l}0.85(0.67-1.08) \\
P=0.20\end{array}$ & 0.01 \\
\hline Model $1^{a}$ & 1 (ref.) & $\begin{array}{l}0.72(0.55-0.93) \\
P=0.01\end{array}$ & $\begin{array}{l}0.88(0.68-1.13) \\
P=0.32\end{array}$ & $\begin{array}{l}0.88(0.68-1.13) \\
P=0.33\end{array}$ & 0.02 \\
\hline Model $2^{b}$ & 1 (ref.) & $\begin{array}{l}0.58(0.38-0.88) \\
P=0.01\end{array}$ & $\begin{array}{l}0.90(0.6-1.33) \\
P=0.59\end{array}$ & $\begin{array}{l}0.79(0.53-1.18) \\
P=0.26\end{array}$ & 0.02 \\
\hline Model $3^{c}$ & 1 (ref.) & $\begin{array}{l}0.63(0.41-0.96) \\
P=0.03\end{array}$ & $\begin{array}{l}0.92(0.61-1.39) \\
P=0.72\end{array}$ & $\begin{array}{l}0.78(0.51-1.17) \\
P=0.23\end{array}$ & 0.08 \\
\hline \multicolumn{6}{|c|}{ Abdominal obesity } \\
\hline Crude & 1 (ref.) & $\begin{array}{l}0.72(0.57-0.91) \\
P=0.006\end{array}$ & $\begin{array}{l}0.82(0.65-1.03) \\
P=0.10\end{array}$ & $\begin{array}{l}0.78(0.62-0.98) \\
P=0.03\end{array}$ & 0.01 \\
\hline Model $1^{a}$ & 1 (ref.) & $\begin{array}{l}0.70(0.53-0.93) \\
P=0.01\end{array}$ & $\begin{array}{l}0.81(0.62-1.07) \\
P=0.14\end{array}$ & $\begin{array}{l}0.75(0.58-0.99) \\
P=0.04\end{array}$ & 0.03 \\
\hline Model $2^{b}$ & 1 (ref.) & $\begin{array}{l}0.66(0.42-1.02) \\
P=0.06\end{array}$ & $\begin{array}{l}0.82(0.54-1.25) \\
P=0.36\end{array}$ & $\begin{array}{l}0.83(0.54-1.26) \\
P=0.38\end{array}$ & 0.08 \\
\hline Model $3^{c}$ & 1 (ref.) & $\begin{array}{l}0.74(0.43-1.27) \\
P=0.28\end{array}$ & $\begin{array}{l}0.86(0.51-1.44) \\
P=0.58\end{array}$ & $\begin{array}{l}0.73(0.43-1.23) \\
P=0.24\end{array}$ & 0.41 \\
\hline \multicolumn{6}{|c|}{ Elevated blood pressure } \\
\hline Crude & 1 (ref.) & $\begin{array}{l}1.28(0.98-1.69) \\
P=0.06\end{array}$ & $\begin{array}{l}1.32(1.01-1.73) \\
P=0.04\end{array}$ & $\begin{array}{l}1.41(1.07-1.85) \\
P=0.01\end{array}$ & 0.01 \\
\hline Model $1^{a}$ & 1 (ref.) & $\begin{array}{l}1.28(0.95-1.72) \\
P=0.09\end{array}$ & $\begin{array}{l}1.32(0.98-1.77) \\
P=0.06\end{array}$ & $\begin{array}{l}1.35(1.01-1.81) \\
P=0.03\end{array}$ & 0.05 \\
\hline Model $2^{b}$ & 1 (ref.) & $\begin{array}{l}0.59(0.38-0.92) \\
P=0.02\end{array}$ & $\begin{array}{l}0.81(0.53-1.22) \\
P=0.31\end{array}$ & $\begin{array}{l}0.96(0.64-1.45) \\
P=0.87\end{array}$ & 0.01 \\
\hline Model $3^{c}$ & 1 (ref.) & $\begin{array}{l}0.62(0.40-0.96) \\
P=0.03\end{array}$ & $\begin{array}{l}0.83(0.55-1.26) \\
P=0.39\end{array}$ & $\begin{array}{l}0.96(0.63-1.45) \\
P=0.84\end{array}$ & 0.03 \\
\hline
\end{tabular}

OR Odds ratio, $\mathrm{Cl}$ Confidence interval, PI phytochemical index, Q quartile

${ }^{a}$ Adjusted for age, sex and energy intake, ${ }^{b}$ Additional adjustment for marriage status, physical activity, education level, smoking, job status, house status, family

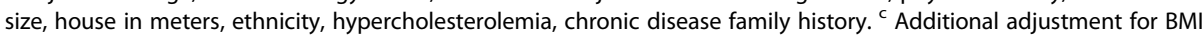

on the relationship between DPI and MetS or its components, the results of this study shine new insights about the relationship between DPI with odds of MetS and its components in a large sample of Iranians adults as a representative of the Middle Eastern countries.

Our results also indicated that a diet with higher DPI was associated with a diminished risk of high blood pressure and MetS. These findings are in agreement with the results of former studies, which reported that higher amounts of vegetables and fruits [32, 33], whole grains [34, 35], nuts [36, 37], legumes [38], are inversely associated with hypertension. Other studies have shown that the consumption of phytochemical abundant foods may prevent hypertension and MetS [39-41]. These findings may be explained by the synergistic effects of phytochemicals together with its antioxidant and antiinflammatory properties, as well as high intake of antioxidant vitamins including vitamin $\mathrm{C}$ and vitamin $\mathrm{A}$ that can inverse insulin resistance [33, 40, 42]. Further evidences suggest the protective effect of a higher intake of potassium and folate on endothelial function, MetS and hypertension [33, 43]. In contrast, a cross-sectional study on Iranian adults observed no significant association between DPI and the odds of hypertension and MetS [44]. Such contradictions may be due to the differences in sampling size and dietary habits.

Our results also showed a significant reverse relationship between abdominal obesity and higher conformity of DPI, which are consistent with a longitudinal study on adults, reporting that an increase in energy intake from phytochemicals-rich foods precludes weight gain and adiposity [45]. A cross-sectional investigation on 54 adults aged between 18 and 30 years showed that DPI score was inversely related to $\mathrm{WC}$ (25). The protective role of phytochemicals against WC may be mediated by inhibitory role of some polyphenols in proliferation of pre-adipocytes, reducing adipogenesis, and stimulating lipolysis [46, 47]. However, our findings did not remain significant after further adjustment for confounders, which may be due to the differences in general and genetic characteristics of the subjects. 
Table 4 OR $(95 \% \mathrm{Cl})$ for metabolic syndrome by quartiles of DPI stratified by gender $(n=2326)$

\begin{tabular}{|c|c|c|c|c|c|}
\hline Sex & Q1 & Q2 & Q3 & Q4 & $P_{\text {trend }}$ \\
\hline \multicolumn{6}{|l|}{ Men } \\
\hline Crude & 1 (ref.) & $\begin{array}{l}0.72(0.49-1.05) \\
P=0.09\end{array}$ & $\begin{array}{l}1.04(0.72-1.49) \\
P=0.83\end{array}$ & $\begin{array}{l}1.03(0.72-1.48) \\
P=0.83\end{array}$ & 0.12 \\
\hline Model $3^{*}$ & 1 (ref.) & $\begin{array}{l}0.54(0.27-1.07) \\
P=0.08\end{array}$ & $\begin{array}{l}1.39(0.77-2.51) \\
P=0.27\end{array}$ & $\begin{array}{l}1.36(0.74-2.40) \\
P=0.31\end{array}$ & 0.15 \\
\hline \multicolumn{6}{|l|}{ Women } \\
\hline Crude & 1 (ref.) & $\begin{array}{l}0.66(0.47-0.92) \\
P=0.01\end{array}$ & $\begin{array}{l}0.72(0.51-1) \\
P=0.05\end{array}$ & $\begin{array}{l}0.73(0.52-1.02) \\
P=0.06\end{array}$ & 0.02 \\
\hline Model $3^{*}$ & 1 (ref.) & $\begin{array}{l}0.74(0.40-1.38) \\
P=0.35\end{array}$ & $\begin{array}{l}0.62(0.34-1.14) \\
P=0.12\end{array}$ & $\begin{array}{l}0.41(0.22-0.76) \\
P=0.005\end{array}$ & 0.70 \\
\hline
\end{tabular}

OR Odds ratio, Cl Confidence interval, DPI Dietary phytochemical index, Q quartile

*Adjusted for age, energy intake, marriage status, physical activity, education level, smoking, job status, house status, family size, house in meters, ethnicity, hypercholesterolemia, chronic disease family history, BMI

In the present study, the analysis stratified by sex showed that odds MetS reduced in women with highest compliance of DPI. In line with our findings, a crosssectional study showed a lower risk of the MetS among women with higher intakes of fruits and vegetables [48]. Another study found that moderate and high intake of fruits could alleviate MetS in women [49]. Some studies have also reported that phytochemicals in food sources could improve lipid metabolism in middle-aged women especially with menopause $[50,51]$. Several possible mechanisms of higher adherence of DPI and MetS in women can be described. For example, women with higher intake of DPI have lower levels of C-reactive protein, oxidative stress and inflammation than men due to an interaction between sex hormones and some phytochemicals intake such as isoflavones with similar structure to estrogen [52-56].

The advantages and limitations of the present study can be summarized as follows. Population-based design was the most important strength of this study. Face-toface interviews in a large sample of population using trained interviewers were other strengths. Dietary intakes were assessed with a validated questionnaire. Nevertheless, the major limitation of the cross-sectional design of this study was rooted in the inability to determine the direction of relations. The possibility of not considering all possible confounders was another one. Also, the dietary phytochemicals quality of the participants in the same DPI was not determined in term of the variation in intake food containing phytochemicals.

\section{Conclusions}

More adherence to DPI is probably related to reduced risk of MetS especially in women. Interventional studies are needed to discover causal relations and relevant underlying mechanisms.

\section{Abbreviations}

DPI: Dietary Phytochemical Index; MetS: Metabolic Syndrome; YaHS: Yazd Health Study; TAMYZ: Taghzieh Mardom-e-YaZd; YNS: Yazd Nutrition Survey; FFQ: Food Frequency Questionnaire; WC: Waist Circumference;

IPAQ: International Physical Activity Questionnaire; MUFA: Monounsaturated Fatty Acids; SFA: Saturated Fatty Acids; PUFA: Polyunsaturated Fatty Acids;

HDL-C: Serum High-Density Lipoprotein Cholesterol; FBS: Fasting Blood

Glucose; DHA: Docosahexaenoic Acid; EPA: Eicosapentaenoic Acid; BMI: Body Mass Index; MET: Metabolic Equivalent; SD: Standard Deviation

\section{Acknowledgements}

We thank all the people who participated in this project and committees that supported the research.

\section{Authors' contributions}

AAV and ZD prepared the proposal, wrote the manuscript and study analysis. $\mathrm{MH}$ conceivedthe idea and supervised the study.MM and AN contributed to the study design. All authors critically reviewed the manuscript and approved the final version for publication.

\section{Funding}

This research was funded by Nutrition and Food Security Research Center, Shahid Sadoughi University of Medical Sciences, Yazd, Iran.

\section{Availability of data and materials}

The YaHS database is closed. The data was provided by the $\mathrm{Cl}$ of the study, professor Masoud Mirzaei in line with the study protocol. http://www.yahsziba.com

\section{Declarations}

Ethics approval and consent to participate

Written informed consent was obtained from all participants. Ethical approval was obtained from the Ethics Committee of Shahid Sadoughi University of Medical Sciences, IR.SSU.SPH.REC.1399.051.

Consent for publication

Not applicable.

\section{Competing interests}

The authors have declared no competing interests.

\section{Author details}

${ }^{1}$ Nutrition and Food Security Research Center, School of Public Health, Shahid Sadoughi University of Medical Sciences, Yazd, Iran. ${ }^{2}$ Department of Nutrition, School of Public Health, Shahid Sadughi University of Medical Sciences, Yazd, Iran. ${ }^{3}$ Yazd Cardiovascular Research Center, Shahid Sadoughi University of Medical Sciences, Yazd, Iran. 
Received: 25 October 2020 Accepted: 3 August 2021 Published online: 24 August 2021

\section{References}

1. Lear SA, Gasevic D. Ethnicity and Metabolic Syndrome: Implications for Assessment, Management and Prevention. Nutrients. 2020;12(1):15.

2. Kurtoglu S, Akin L, Kendirci M, Hatipoglu N, Elmali F, Mazicioglu M. The absence of insulin resistance in metabolic syndrome definition leads to underdiagnosing of metabolic risk in obese patients. Eur J Pediatr. 2012; 171(9):1331-7. https://doi.org/10.1007/s00431-012-1724-6.

3. Practice CRA. Retracted: a comprehensive review on metabolic syndrome. Cardiol Res Pract. 2019;2019:4301528.

4. Shirani F, Esmaillzadeh A, Keshteli AH, Adibi P, Azadbakht L. Lowcarbohydrate-diet score and metabolic syndrome: an epidemiologic study among Iranian women. Nutrition. 2015;31(9):1124-30. https://doi.org/10.101 6/j.nut.2015.04.013

5. Povel CM, Boer JM, Onland-Moret NC, Dollé ME, Feskens EJ, van der Schouw YT. Single nucleotide polymorphisms (SNPs) involved in insulin resistance, weight regulation, lipid metabolism and inflammation in relation to metabolic syndrome: an epidemiological study. Cardiovasc Diabetol. 2012;11(1):133. https://doi.org/10.1186/1475-2840-11-133.

6. Kaur J. Assessment and screening of the risk factors in metabolic syndrome. Med Sci. 2014;2(3):140-52. https://doi.org/10.3390/medsci2030140.

7. Reaven GM. Diet and syndrome X. Curr Atheroscler Rep. 2000;2(6):503-7. https://doi.org/10.1007/s11883-000-0050-z.

8. Klemsdal TO, Holme I, Nerland H, Pedersen TR, Tonstad S. Effects of a low glycemic load diet versus a low-fat diet in subjects with and without the metabolic syndrome. Nutr Metab Cardiovasc Dis. 2010;20(3):195-201. https://doi.org/10.1016/j.numecd.2009.03.010.

9. Feldeisen SE, Tucker KL. Nutritional strategies in the prevention and treatment of metabolic syndrome. Appl Physiol Nutr Metab. 2007;32(1):4660. https://doi.org/10.1139/h06-101.

10. Lutsey PL, Steffen LM, Stevens J. Dietary intake and the development of the metabolic syndrome. Circulation. 2008;117(6):754-61. https://doi.org/10.11 61/CIRCULATIONAHA.107.716159.

11. LaHaye SA, Hollett PM, Vyselaar JR, Shalchi M, Lahey KA, Day AG. Comparison between a low glycemic load diet and a Canada food guide diet in cardiac rehabilitation patients in Ontario. Can J Cardiol. 2005;21(6): 489-94.

12. Castanho GKF, Marsola FC, Mclellan KCP, Nicola M, Moreto F, Burini RC. Consumption of fruit and vegetables associated with the metabolic syndrome and its components in an adult population sample. Cien Saude Colet. 2013;18(2):385-92. https://doi.org/10.1590/S1413-81232013 000200010 .

13. Hu FB. Dietary pattern analysis: a new direction in nutritional epidemiology. Curr Opin Lipidol. 2002;13(1):3-9. https://doi.org/10.1097/00041433-200202 000-00002.

14. van Dam RM. New approaches to the study of dietary patterns. Br J Nutr. 2005;93(5):573-4. https://doi.org/10.1079/bjn20051453.

15. Mirzababaei A, Sajjadi SF, Ghodoosi N, Pooyan S, Arghavani H, Yekaninejad MS, et al. Relations of major dietary patterns and metabolically unhealthy overweight/obesity phenotypes among Iranian women. Diabetes Metab Syndr Clin Res Rev. 2019;13(1):322-31. https://doi.org/10.1016/j.dsx.2018.09. 012.

16. Farhangi MA, Najafi M, Jafarabadi MA, Jahangiry L. Mediterranean dietary quality index and dietary phytochemical index among patients candidate for coronary artery bypass grafting (CABG) surgery. BMC Cardiovasc Disord. 2017;17(1):114. https://doi.org/10.1186/s12872-017-0544-z.

17. McCarty MF. Proposal for a dietary "phytochemical index". Med Hypotheses. 2004;63(5):813-7. https://doi.org/10.1016/j.mehy.2002.11.004.

18. Bahadoran Z, Mirmiran P, Tohidi M, Azizi F. Dietary phytochemical index and the risk of insulin resistance and $\beta$-cell dysfunction: a prospective approach in Tehran lipid and glucose study. Int J Food Sci Nutr. 2015;66(8): 950-5. https://doi.org/10.3109/09637486.2015.1111867.

19. Bahadoran Z, Golzarand M, Mirmiran P, Saadati N, Azizi F. The association of dietary phytochemical index and cardiometabolic risk factors in adults: Tehran lipid and glucose study. J Hum Nutr Diet. 2013;26:145-53. https:// doi.org/10.1111/jhn.12048.

20. Mofrad MD, Siassi F, Guilani B, Bellissimo N, Azadbakht L. Association of dietary phytochemical index and mental health in women: a cross-sectional study. Br J Nutr. 2019;121(9):1049-56. https://doi.org/10.1017/S000711451 9000229.

21. Mirzayi BR. Dietary phytochemical index and the risk of breast cancer: a case control study in a population of Iranian women. Asian Pac J Cancer Prev. 2013;14(5):2747-51.

22. Vincent HK, Bourguignon CM, Taylor AG. Relationship of the dietary phytochemical index to weight gain, oxidative stress and inflammation in overweight young adults. J Hum Nutr Diet. 2010;23(1):20-9. https://doi. org/10.1111/j.1365-277X.2009.00987.X.

23. Keaney JF Jr, Larson MG, Vasan RS, Wilson PW, Lipinska I, Corey D, et al. Obesity and systemic oxidative stress: clinical correlates of oxidative stress in the Framingham study. Arterioscler Thromb Vasc Biol. 2003;23(3):434-9. https://doi.org/10.1161/01.ATV.0000058402.34138.11.

24. Hanhineva K, Törrönen R, Bondia-Pons I, Pekkinen J, Kolehmainen M, Mykkänen $\mathrm{H}$, et al. Impact of dietary polyphenols on carbohydrate metabolism. Int J Mol Sci. 2010;11(4):1365-402. https://doi.org/10.3390/ ijms11041365.

25. Kahleova H, Matoulek M, Malinska H, Oliyarnik O, Kazdova L, Neskudla T, et al. Vegetarian diet improves insulin resistance and oxidative stress markers more than conventional diet in subjects with type 2 diabetes. Diabet Med. 2011;28(5):549-59. https://doi.org/10.1111/j.1464-5491.2010.032 09.x.

26. Abshirini M, Mahaki B, Bagheri F, Siassi F, Koohdani F, Sotoudeh G. Higher intake of phytochemical-rich foods is inversely related to prediabetes: a case-control study. Int J Prev Med. 2018;9(1):64.

27. Mirzaei M, Salehi-Abargouei A, Mirzaei M, Mohsenpour MA. Cohort Profile: The Yazd Health Study (YaHS): a population-based study of adults aged 2070 years (study design and baseline population data). Int J Epidemiol. 2018; 47(3):697-698h.

28. Esfahani FH, Asghari G, Mirmiran P. F a: reproducibility and relative validity of food group intake in a food frequency questionnaire developed for the Tehran lipid and glucose study. J Epidemiol. 2010;20(2):150-8. https://doi. org/10.2188/jea.JE20090083.

29. Ghafarpour M, Houshiar-Rad A, Kianfar H. The manual for household measures, cooking yields factors and edible portion of food.Tehran: Nashre Olume Keshavarzy. 1999;7(213):42-58.

30. Moghaddam MB, Aghdam FB, Jafarabadi MA, Allahverdipour $H$, Nikookheslat SD, Safarpour S, et al. The Iranian version of International Physical Activity Questionnaire (IPAQ) in Iran: content and construct validity, factor structure, internal consistency and stability. World Appl Sci J. 2012; 18(8):1073-80

31. Alberti K. International diabetes federation task force on epidemiology and prevention; hational heart, lung, and blood institute; American heart association; world heart federation; international atherosclerosis society; international association for the study of obesity: harmonizing the metabolic syndrome: a joint interim statement of the international diabetes federation task force on epidemiology and prevention; national heart, lung, and blood institute; American heart association; world heart federation; international atherosclerosis society; and international association for the study of obesity. Circulation. 2009;120:1640-5.

32. Miura K, Greenland P, Stamler J, Liu K, Daviglus ML, Nakagawa H. Relation of vegetable, fruit, and meat intake to 7-year blood pressure change in middle-aged men: the Chicago Western electric study. Am J Epidemiol. 2004;159(6):572-80. https://doi.org/10.1093/aje/kwh085.

33. Utsugi MT, Ohkubo T, Kikuya M, Kurimoto A, Sato Rl, Suzuki K, et al. Fruit and vegetable consumption and the risk of hypertension determined by self measurement of blood pressure at home: the Ohasama study. Hypertens Res. 2008;31(7):1435-43. https://doi.org/10.1291/hypres.31.1435.

34. Wang L, Gaziano JM, Liu S, Manson JE, Buring JE, Sesso HD. Whole-and refined-grain intakes and the risk of hypertension in women. Am J Clin Nutr. 2007:86(2):472-9. https://doi.org/10.1093/ajcn/86.2.472.

35. Flint AJ, Hu FB, Glynn RJ, Jensen MK, Franz M, Sampson L, et al. Whole grains and incident hypertension in men. Am J Clin Nutr. 2009;90(3):493-8. https://doi.org/10.3945/ajen.2009.27460.

36. Djoussé L, Rudich T, Gaziano JM. Nut consumption and risk of hypertension in US male physicians. Clin Nutr. 2009;28(1):10-4. https://doi.org/10.1016/j. clnu.2008.08.005.

37. Weng L-C, Steffen LM, Szklo M, Nettleton J, Chambless L, Folsom AR. A diet pattern with more dairy and nuts, but less meat is related to lower risk of developing hypertension in middle-aged adults: the atherosclerosis risk in 
communities (ARIC) study. Nutrients. 2013;5(5):1719-33. https://doi.org/10.33 90/nu5051719.

38. Hosseinpour NS, Mirmiran P, Amiri Z, Hosseini EF, Shakeri N, Azizi F. Legume intake is inversely associated with metabolic syndrome in adults. Arch Iran Med. 2012;15(9):538-44.

39. Golzarand M, Bahadoran Z, Mirmiran P, Sadeghian-Sharif S, Azizi F. Dietary phytochemical index is inversely associated with the occurrence of hypertension in adults: a 3-year follow-up (the Tehran lipid and glucose study). Eur J Clin Nutr. 2015;69(3):392-8. https://doi.org/10.1038/ejcn.2 014.233.

40. Bahadoran Z, Golzarand M, Mirmiran P, Amouzgar A, Azizi F. Association between dietary phytochemical index and occurrence of metabolic syndrome and its risk factors (among Tehranian adults): Tehran lipid and glucose study. Iran J Endocrinol Metab. 2012;14(4):343-51.

41. Kim M, Park K. Association between phytochemical index and metabolic syndrome. Nutr Res Pract. 2020;14(3):252-61. https://doi.org/10.4162/nrp.202 0.14.3.252.

42. Ness A, Chee D, Elliott P. Vitamin C and blood pressure-an overview. J Hum Hypertens. 1997;11(6):343-50. https://doi.org/10.1038/sj.jhh.1000423.

43. Xun P, Liu K, Loria CM, Bujnowski D, Shikany JM, Schreiner PJ, et al. Folate intake and incidence of hypertension among American young adults: a 20-y follow-up study. Am J Clin Nutr. 2012;95(5):1023-30. https://doi.org/10.394 5/ajcn.111.027250.

44. Dehghani Firouzabadi F, Jayedi A, Asgari E, Farazi M, Noruzi Z, Djafarian K, et al. The Association of Dietary Phytochemical Index with metabolic syndrome in adults. Clin Nutr Res. 2021;10(2):161-71. https://doi.org/10. 7762/cnr.2021.10.2.161.

45. Mirmiran P, Bahadoran Z, Golzarand M, Shiva N, Azizi F. Association between dietary phytochemical index and 3-year changes in weight, waist circumference and body adiposity index in adults: Tehran lipid and glucose study. Nutr Metab. 2012;9(1):108. https://doi.org/10.1186/1743-7075-9-108.

46. Tucci SA. Phytochemicals in the control of human appetite and body weight Pharmaceuticals. 2010;3(3):748-63. https://doi.org/10.3390/ph3030748.

47. Golzarand M, Mirmiran P, Bahadoran Z, Alamdari S, Azizi F. Dietary phytochemical index and subsequent changes of lipid profile: a 3-year follow-up in Tehran lipid and glucose study in Iran. ARYA Atheroscler. 2014; 10(4):203-10

48. Esmaillzadeh A, Kimiagar M, Mehrabi Y, Azadbakht L, Hu FB, Willett WC. Fruit and vegetable intakes, $\mathrm{C}$-reactive protein, and the metabolic syndrome. Am J Clin Nutr. 2006;84(6):1489-97. https://doi.org/10.1093/ajcn/84.6.1489.

49. Park S, Ham J-O, Lee B-K. Effects of total vitamin a, vitamin C, and fruit intake on risk for metabolic syndrome in Korean women and men. Nutrition. 2015;31(1):111-8. https://doi.org/10.1016/j.nut.2014.05.011.

50. Hong SA, Kim MK. Relationship between fruit and vegetable intake and the risk of metabolic syndrome and its disorders in Korean women according to menopausal status. Asia Pac J Clin Nutr. 2017;26(3):514-23. https://doi.org/1 0.6133/apjcn.042016.03.

51. Ko S-H, Kim H-S. Menopause-associated lipid metabolic disorders and foods beneficial for postmenopausal women. Nutrients. 2020;12(1):202. https://doi. org/10.3390/nu12010202

52. Hasler CM, Brown AC, American Dietetic A. Position of the American Dietetic Association: Functional foods. J Am Diet Assoc. 2009;109(4):735-46.

53. Srinivasan K. Biological activities of red pepper (Capsicum annuum) and its pungent principle capsaicin: a review. Crit Rev Food Sci Nutr. 2016;56(9): 1488-500. https://doi.org/10.1080/10408398.2013.772090.

54. Keihanian F, Saeidinia A, Bagheri RK, Johnston TP, Sahebkar A. Curcumin, hemostasis, thrombosis, and coagulation. J Cell Physiol. 2018;233(6):4497511. https://doi.org/10.1002/jcp.26249.

55. Hong J, Kim S-S, Kim HS. Hepatoprotective Eects of Soybean Embryo by Enhancing Adiponectin-Mediated AMP-Activated Protein Kinase alpha Pathway in High-Fat and High-Cholesterol Diet-Induced Nonalcoholic Fatty Liver Disease. J Med Food. 2016;19(6):549-59.

56. Holubkova A, Penesová A, Sturdik E, Mosovska S, Mikusova L. Phytochemicals with potential effects in metabolic syndrome prevention and therapy. Acta Chim Slov. 2012;5(2):186-99.

\section{Publisher's Note}

Springer Nature remains neutral with regard to jurisdictional claims in published maps and institutional affiliations. 